\title{
Assessment of anti-psoriatic activity of ethanolic extract of Justicia tranquebariensis Linn. on amelioration of IMQ-induced hyperkeratosis in Balb/C mice
}

\author{
Divya Bharathi ${ }^{1}$, Latha Subbiah ${ }^{1}$, Prabha Thangavelu ${ }^{2}$, Selvamani Palanisamy ${ }^{1 *}$ \\ ${ }^{1}$ Department of Pharmaceutical Technology, Centre for Excellence in Nanobio Translational Research, Anna University, Bharathidasan Institute of Technology \\ Campus, Tiruchirappalli, India. \\ ${ }^{2}$ Department of Pharmaceutical Chemistry, Nandha College of Pharmacy, Koorapalayam Pirivu, Erode, India.
}

\begin{tabular}{l}
\hline ARTICLE INFO \\
\hline Received on: 05/09/2019 \\
Accepted on: $25 / 04 / 2020$ \\
Available online: $05 / 12 / 2020$
\end{tabular}

Key words:

Justicia tranquebariensis, anti-psoriatic effect,

IMQ-induced psoriasis, isolariciresinol, histopathological study.

\begin{abstract}
Psoriasis characterized by abnormal keratinocyte hyper proliferation results in the thickening of the epidermis and the stratum corneum. Anti-psoriasis treatments available today are poorly efficient, having many side effects, making them unsuitable for therapeutic use. Hence, the search for safer and more effective drugs from natural resources is necessarily warranted. In the present study, the leaves of Justicia tranquebariensis Linn. have been evaluated for its anti-psoriatic activity to substantiate the traditional claim as an anti-psoriatic agent scientifically. Additionally, an EJTL ointment was formulated for the in vivo anti-psoriatic evaluation in Balb/c mice together with its histopathological study. The obtained results revealed the presence of primary phytochemicals, such as flavonoids and lignans in the ethanol extract of the leaves of $J$. tranquebariensis L. (EJTL). Furthermore, the UV-Visible and Fourier Transform Infrared Spectrums confirmed the existence of the relevant functional groups supports the presence of Isolariciresinol in the EJTL ethanol extract. In vivo evaluation of the EJTL ointment showed the remarkable anti-psoriatic activity in Balb/c mice with imiquimod (IMQ) induced psoriasis-like inflammation. The histopathological study results revealed significant improvement in skin lesion when compared to the positive control group. The anti-psoriatic activity further confirmed by observing the prominently decreased lymphocyte and keratinocyte infiltration in the dermis. A brief phytochemical characterization showed the presence of the active botanical ingredient, Isolariciresinol, assumed to have the anti-psoriatic property. Furthermore, the EJTL could be a potential drug for psoriasis either individually or synergistically with other herbals or anti-psoriatic agents.
\end{abstract}

\section{INTRODUCTION}

Psoriasis is a chronic, recurrent, immune-mediated inflammatory disease characterized by the irregular keratinocyte hyper propagation resulting in flaking, inflammation, and

\section{${ }^{*}$ Corresponding Author}

Selvamani Palanisamy, Department of Pharmaceutical Technology, Centre for Excellence in Nanobio Translational Research, Anna University, Bharathidasan Institute of Technology Campus, Tiruchirappalli, India. E-mail: selva.autpharma1@gmail.com thickening of epidermis and stratum corneum leads to white, silver, or red patches of the skin. The etiology for the exact cause of psoriasis remains uncertain. Probably, the primary immune defect appears to be responsible for the increase in cell signaling via chemokines and cytokines that act up-regulating gene expression, causing keratinocyte hyperproliferation (Yujiao et al., 2017).

Psoriasis development depends on skin infiltration of $\mathrm{T}$ helper 1/T helper 17 (Th1/Th17) cells that stimulate macrophages and dermal dendritic cells to release mediators that sustain inflammation and cause abnormal keratinocyte proliferation. Interleukin (IL)-23, a cytokine, has the potential to activate the Th17 cells, stimulating their survival and replication, and serving as a master regulator in psoriasis 
(Blauvelt, 2008). The psoriatic patients experience increased activity of Th17 cell, whereas psoriasis has improved through reducing Th17 activity. The IL-17, IL-21, and IL-22 secreted by Th17 cells, and cytokines mediate the IL-23 cell-induced acanthosis and dermal irritation (Zheng et al., 2007). Consequently, the IL-23 and Th17 together will take part in psoriasis and explains the hyperplasia of psoriatic keratinocytes.

Owing to inadequate diagnosis and treatment in the present scenario, there are many patients suffer from psoriasis and associated complaints. According to the World Health Organization report, the psoriasis is the disease that could occur at any stage of our life, and it is most commonly in the age group of 50-69. There is an increase in the prevalence of psoriasis noticed from $0.09 \%$ to $11.4 \%$, which makes this condition an unadorned health problem. In most developed countries, the incidence of psoriasis is between $1.5 \%$ and $5 \%$ (Parisi et al., 2013).

Phytochemical researchers always attempt to discover new and efficient pharmaceutical leads from herbs that seem vital for drug discovery and development. Most of the reported plantbased natural products were considered promising as therapeutic agents because of their low toxicity, specificity to targets, relatively low cost, acceptability, and easy availability. Many plant extracts have used as primary components in many pharmaceutical and cosmetic topical formulations due to their different functional and therapeutic properties. Therefore, it has proposed herein to find out the potential active ingredients to treat skin disorders, especially psoriasis using herbal extracts.

Justicia tranquebariensis Linn. Family, Acanthaceae, was selected for our study based on the traditional claim for its use for treating skin infections. Based on the literature survey of the previously reported work on this plant, it has confirmed that the $J$. tranquebariensis leaves abundantly used as Anti-inflammatory (Akilandeswari et al., 2001), Cardioprotective (Radhika et al., 2013), Anti-arthritic (Senthamarai et al., 2013), Antiulcerogenic (Shabana and Muhammad, 2015), Hepatoprotective (Shabana et al., 2011), Bronchial asthma (Velpandian et al., 2014), Antihelmenthic (Jiju, 2015), Antioxidant (Krishnamoorthi and Ratha Bai, 2015), and Antibacterial activities (Shabana et al., 2008).

On the other hand, its remedial perspective is perceptible to its phytochemical constituents. The studies on the leaves of $J$. tranquebariensis confirms the occurrence of lignans, phytosterols, flavonoids, glycosides, lignans, etc. (Pavithra et al., 2017). Various researchers worked on this aerial parts of the plant, which showed significant constituents belongs to the class lignans, such as aryltetralin, (-)-beta-Cubebin, $(+)$-Lariciresinol, $(+)-$ isolariciresinol, $(+)$-Lyoniresinol, and $(+)$ - Medioresinol through the spectral data analysis [16]. Based on the previous report, the Lariciresinol and Isolariciresinol were confirmed to have the antiinflammatory, antinociceptive, anti-ulcerogenic, antimicrobial, cytotoxic, and antioxidant activities (Pavithra et al., 2017). The isolated compounds, like Cubebin have anti-inflammatory activity and Lyoniresinol possess antioxidative, and antimutagenic activity (Saritha and Brindha, 2013).

Based on the above facts, the present study strategy was focused to extract the active components from the leaves of $J$. tranquebariensis L. with $95 \%$ ethanol followed by its phytochemical screening and its in vivo anti-psoriatic evaluation on Balb/c mice with Imiquimod (IMQ) induced psoriasis-like inflammation along with histopathological evaluation of the skin lesions to scientifically support the traditional claim of $J$ tranquebariensis $\mathrm{L}$ as anti-psoriatic agent.

\section{MATERIALS AND METHODS}

\section{Collection of plant}

The whole plant of $J$. tranquebariensis L was collected during the flowering period of October to November 2015 and authenticated by the Botanical Survey of India, Southern Regional Centre, Coimbatore (voucher specimen no. is 1781). The leaves were isolated from the fresh plants, shade dried, and $250 \mathrm{~g}$ of powdered leaves were defatted with Petroleum ether and then exhaustively extracted with $95 \%$ aqueous ethanol in Soxhlet extractor, and the obtained extract has further concentrated in a rotary evaporator.

\section{Phytochemical screening}

The EJTL has screened for the presence of various phytoconstituentsviz. phytosterols, lignans, alkaloids, flavonoids, tannins, saponins, triterpenoids, and glycosides (Harborne, 1973; Sahira Banu and Cathrine, 2015). Further, EJTL was characterized by UV-Visible and FT-IR spectrophotometer to identify the functional groups present in it.

\section{Preparations of plant extract ointment}

An EJTL ointment (10 g) prepared by taking $1 \mathrm{~g}$ of the plant extract was incorporated into $9 \mathrm{~g}$ of simple ointment by trituration method and used for the in vivo study.

\section{In vivo evaluation of anti-psoriatic activity in $\mathrm{Balb} / \mathrm{C}$ mice}

\section{Experimental animals and ethical considerations}

Either sex of Balb/c Mice (18-22 g) has procured from the National Institute of Nutrition, Hyderabad used for this study. After the arrival, the animals were placed randomly and allocated to treatment groups in polypropylene cages with paddy husk as bedding. Animals have housed at a temperature of $24 \pm 2{ }^{\circ} \mathrm{C}$ and relative humidity of $30 \%-70 \%$ at $12: 12$ light:dark cycle has followed throughout the study duration. All mice were allowed water ad libitum and fed with commercial rat/mice chaw $(\mathrm{M} / \mathrm{s}$. Hindustan Lever Ltd, Mumbai). The procedure and protocol for conducting the animal study were assessed and accepted by the Institutional Animal Ethics committee (REF.NO. AUC/IAEC/ JULY-2015-007 DT.16.07.2015).

The animals have divided into four groups of five mice in each. Based on the available report (Kumaresh and Chowdhury, 2015), the topical application of 5\% cream of (IMQ; $20 \mathrm{mg} / \mathrm{cm}^{2}$ ) on the right ear of the all the group mice excluding normal control group was received continuously for 10 days has developed the skin irritation and redness.

- Group-I: Received Vaseline and denoted as Normal control group of mice.

- Group-II: Received 5\% cream of IMQ (20 mg/cm²) on inside of the right ear for 10 days consecutively and denoted as Positive control group of mice.

- Group-III: Received $40 \mathrm{mg} / \mathrm{cm}^{2}$ Clobetasol propionate cream and marked as Standard group of mice.

- Group-IV: Received $100 \mathrm{mg} / \mathrm{cm}^{2}$ of EJTL ointment (topical application) and assigned as Treatment group. 
All the mice have received the treatments from the day one administration of IMQ, once per day for 10 consecutive days. After that, the animals have sacrificed under mild ether anesthesia, and the skin lesions have evaluated through histopathological studies.

\section{Assessment of ear thickness}

The ear thickness has assessed through a thickness gauge instrument at $0,2,4,6,8$, and 10 days intervals. The indication of the extent/decrease of inflammation has established through the measurement of ear thickness (Nadeem et al., 2017).

\section{Assessment of severity of skin inflammation score}

Based on the clinical Psoriasis Area and Severity Index, the severity of the skin inflammation score has processed through an objective scoring system. The following conditions such as erythema, scaling, and thickening of the skin, were scored individually on a scale from 0 to 4 (0-None; 1-Slight; 2-Moderate; 3-Marked; 4-Very Marked) and has observed by red stains. The summation of erythema, scaling, and thickening, i.e., the cumulative score, was used to measure the severity of the inflammation (scale 0-12).

\section{Histopathological studies}

At the end of the experimental Day 10, the ear samples from each mouse were collected immediately upon dissection and preserved in 10\% formalin solution. The samples have further embedded in paraffin for sectioning using a microtome. The obtained $4 \mu \mathrm{m}$ thickness sections have stained by using hematoxylin and eosin (H\&E) stain, and the histopathological studies have performed (Nakaguma et al., 1995; Singhal and Kansara, 2012). The ear tissue pathology has studied beneath a light microscope (Olympus BX43, Tokyo, Japan) for the result interpretation.

\section{Statistical analysis}

All the experiments have repeated three times, and the obtained data has subjected to two-way analysis of variance test. Data with $p<0.05$ was considered statistically significant.

\section{RESULTS}

The phytochemical constituents of the plant extracts of $J$. tranquebariensis leaves has presented in Table 1.

Table 1. Phytochemical investigation results of plant extract of $J$. tranquebariensis leaves.

\begin{tabular}{clcc}
\hline S. No. & Phytochemicals & $\begin{array}{c}\text { Pet ether extract of } \\
\text { J. tranquebariensis }\end{array}$ & $\begin{array}{c}\text { Ethanolic extract of } \\
\text { J. tranquebariensis }\end{array}$ \\
\hline 1. & Glycosides & - & + \\
2. & Alkoloids & - & - \\
3. & Tannins & - & - \\
4. & Saponins & - & - \\
5. & Phytosterols & + & + \\
6. & Flavanoids & + & + \\
7. & Triterpenoids & - & - \\
8. & Lignans & + & + \\
\hline
\end{tabular}

\section{UV-Visible spectrophotometry}

The UV-Visible spectrophotometry showed the maximum absorption at $281 \mathrm{~nm}$. Hence, the absorbance measured at $281 \mathrm{~nm}$ for three dilutions of the EJTL. The results summarized in Figure 1.

\section{Fourier transform infra-red spectrophotometry}

The FT-IR Spectrum of the Petroleum ether extract of $J$. tranquebariensis shows the presence of flavonoids and phytosterols, which is further confirmed by its peak position at 8, 9, and 20 in FT-IR chromatogram (Fig. 2). Whereas, the EJTL spectral data showed the presence of $(+)$ isolariciresinol, which is an active compound present in $J$. tranquebariensis (Raju and Pillai, 1989).

\section{Anti-psoriatic activity}

An immune activator, IMQ, was used topically for the prophylactic therapy of genital and perianal warts caused by human papillomavirus (Leslie et al., 2009). The plasmacytoid dendritic cell ( $\mathrm{pDC}$ ) is the skin infiltration condition that is the hallmark of IMQ induced psoriasis, where the skin directs the rapid influx of pDC (Palamara et al., 2001). The IMQ persuades the relocation of Langerhans cells (LC) upon its local application. However, the Th1 responses on the skin has induced by the maturation of $\mathrm{pDC}$, and the increase in cytokine construction stimulated through keratinocytes, both were encouraged by IMQ treatment in an animal model (Fujisawa et al., 1996; Gibson et al., 2002; Kono et al., 1994; Wagner et al., 1999).

The psoriasis-like hyperkeratosis induced through IMQ $(5 \%)$ cream on the right ear of the Balb/C mice for 10 days. The right ear of the mice has experienced a significant increase in its thickness, which was noticed after the 2 days

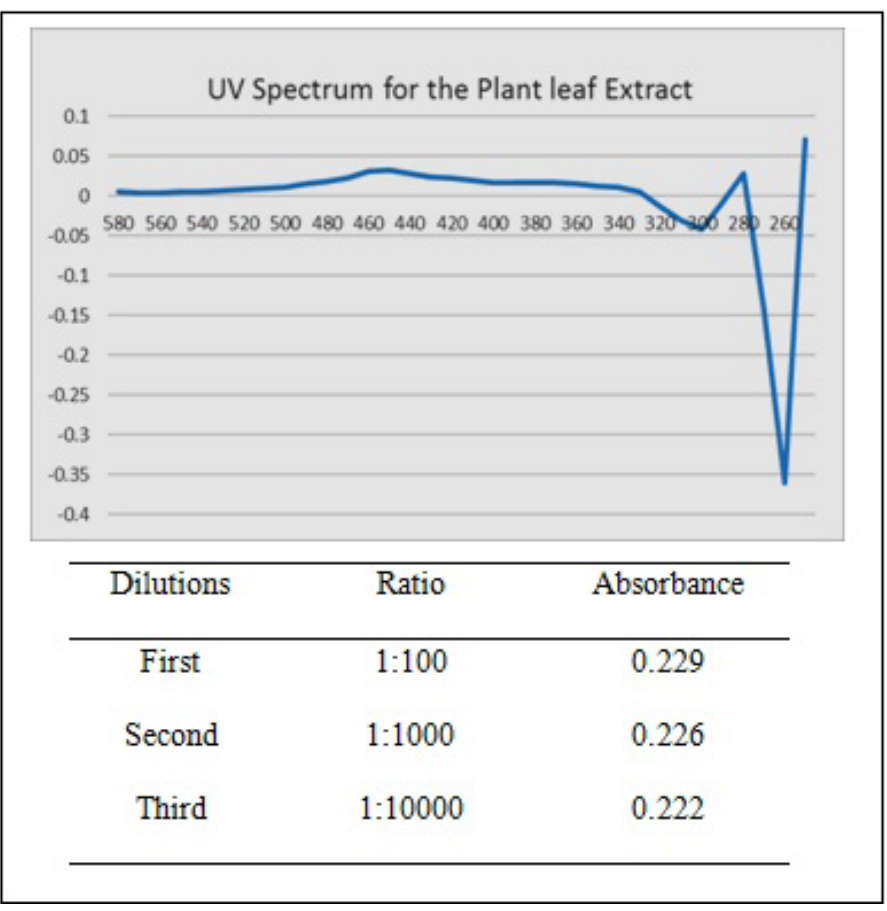

Figure 1. UV-spectrum of ethanolic extract of J. tranquebariensis. 
of the IMQ application and progressed to develop the signs of erythema, scaling, and thickening. The swelling was noticeable in the positive control group and was consequently increased at the end of the trial, whereas the mice received Vaseline did not show any signs of swelling on the right ear of the mice. The mice treated with EJTL ointment $\left(100 \mathrm{mg} / \mathrm{cm}^{2}\right)$ showed comparable results as compared to that of the mice treated with the standard drug $\left(40 \mathrm{mg} / \mathrm{cm}^{2}\right.$, Clobetasol propionate). The screw gauge has used to measure the ear thickness during the entire treatment regime. The variation in the ear thickness measured reflects the degree of inflammation, and the results were presented in Figure $3 \mathrm{~A}$.

The mice treated with IMQ demonstrated the pathological changes, includes psoriasis-like dermatitis, significant parakeratosis, and perivascular infiltration of inflammatory cells in the superior epidermis. The sum of erythema, thickening, and scaling were processed individually on severity scoring scale ranging from 0 to 4 , and the results were established in Figure 3B.

The attenuation of IMQ-induced psoriasis has evidenced through a significant reduction in the thickness of ear epidermis upon treatment with EJTL ointment $\left(100 \mathrm{mg} / \mathrm{cm}^{2}\right)$. The EJTL ointment treated group was comparable to the standard drugtreated group similar in terms of reduction of inflammation severity scores concludes that the EJTL ointment is a potential formulation for the treatment of psoriasis.

\section{Histopathological studies}

The IMQ treatment outcome has assessed through the increased proliferation and distorted discrimination of keratinocytes. The H\&E-stained sections of the histopathological analysis showed the IMQ-treated skin illustrated the augmented

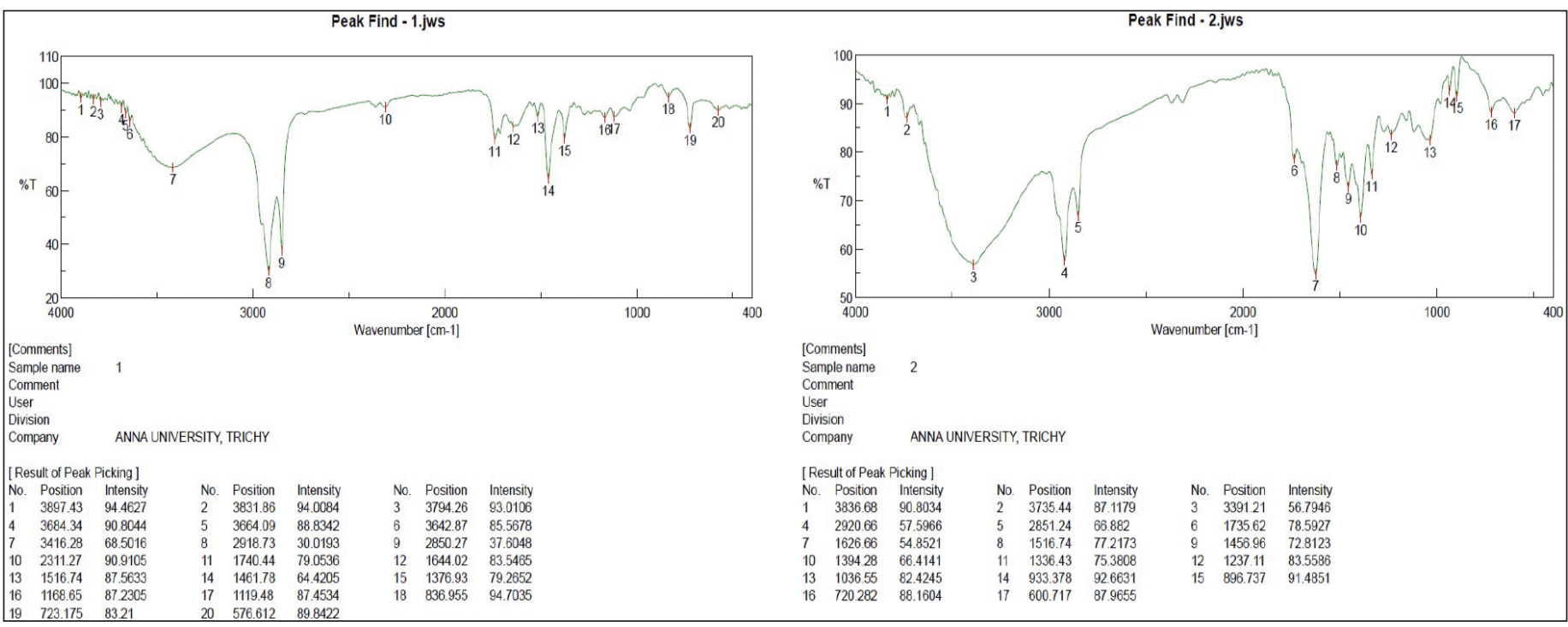

Figure 2. FT-IR Spectrum for the extracts of J. tranquebariensis. Pet. ether extract of $J$. tranquebariensis. Ethanolic extract of $J$. tranquebariensis.

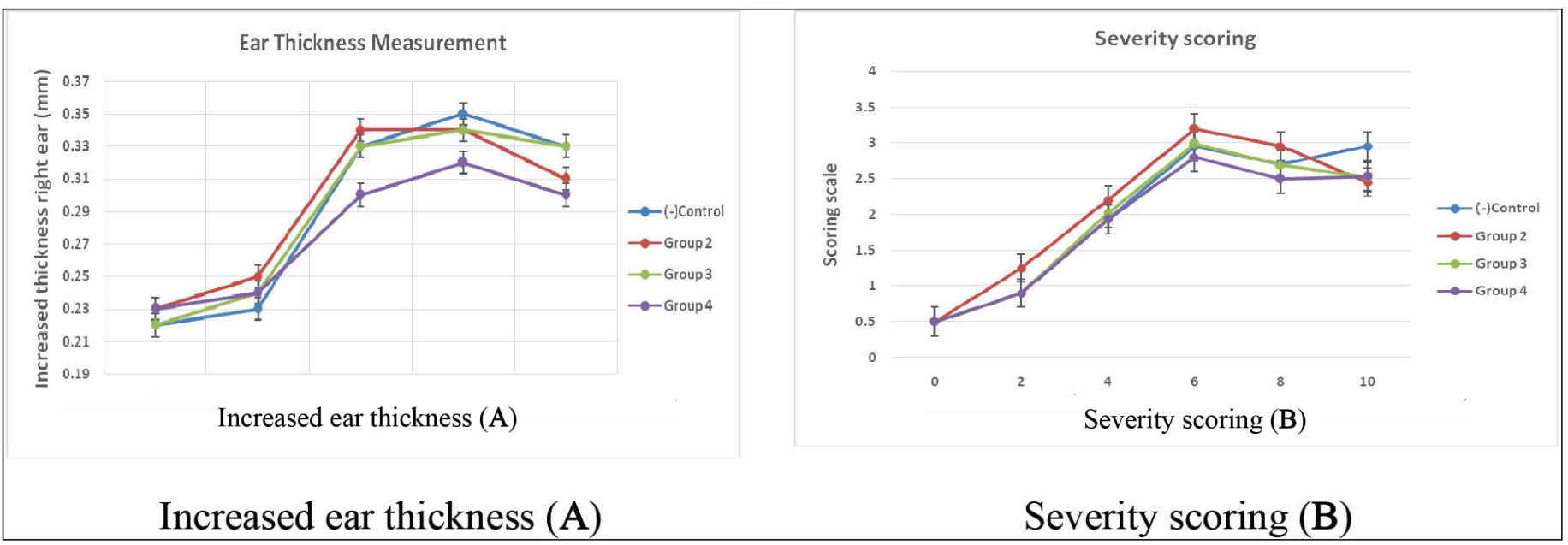

Figure 3. Graphical representation of increased ear thickness (A) and severity scoring (B). Here, The Scoring Scale is 0 -None; 1 -Slight; $2-$ Moderate; 3 -Marked; 4-Very Marked. 
thickening of the ear skin epidermal, which was rooted by hyperproliferation of keratinocytes, and this condition is called acanthosis.

From the histopathological report, it has found that in the negative control group, the dermis appeared normal (Fig. 4 and Table 2). Besides, the granular layer was not presented in IMDinduced skin lesions, whereas it has noticed in the control group mice. The distorted epidermal discrimination is the indication of parakeratosis of the skin, which is a characteristic indication of psoriasis-like hyperkeratosis that has assessed via scaling. Upon microscopical examination of the H\&E-stained sections of the IMQ-treated mice, it has observed that there is the retention of nuclei in the stratum corneum of the skin. Also, these tissue sections showed pinna with moderate hyperkeratosis, keratin flaking, and the upper dermis showed many lymphocytes and absence of granular cell layer. Also, there is no elongation of rete-ridges, and there is a dense infiltration by polymorphs in the parakeratosis layer.

The IMQ administered mice skin has treated with EJTL ointment $\left(100 \mathrm{mg} / \mathrm{cm}^{2}\right)$ had shown the epidermis with thinning of granular cell layer, indicating that it influences to retard the hyperproliferation of the keratinocytes. Moreover, it shows a dense infiltration by lymphocytes and polymorphs and pinna with skin surface having mild hyperkeratosis and moderate lymphocytic

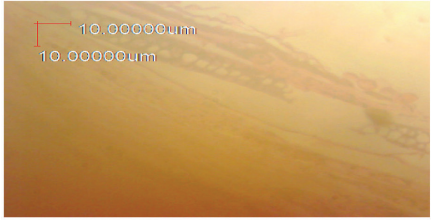

Negative control group (Vaseline)

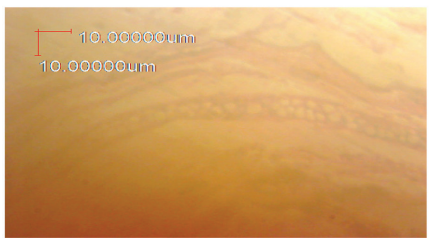

Standard group $\left(40 \mathrm{mg} / \mathrm{cm}^{2}\right)$ Clobetasol Treatment group $\left(100 \mathrm{mg} / \mathrm{cm}^{2}\right)$ EJTL ointment propionate cream

Figure 4. Hematoxylin and eosin stained microscopic slide images for the indication of histopathological features on IMQ induced psoriasis in EJTL treated rats. infiltration. The significant retention of the stratum granulosum is probably due to its ability to enhance the keratinization process, which is a protective strategy adopted by the skin when exposed to IMQ treatment. The samples of mice from all four groups were analyzed histopathologically, and the images showing dermal differences presented in Figure 4.

\section{DISCUSSION}

There is an increasing trend in research on medicinal plants focused on identifying therapeutically valued ingredients for the treatment of various ailments, especially curing the diverse inflammation condition with few or no side effects. Research reports showed that the lignan, isolariciresinol, a promising metabolite from $J$. tranquebariensis, was used to treat the inflammation condition (Akilandeswari et al., 2001; Xiao et al., 2014) through down-regulating the keratinocyte inflammation.

Psoriasis, a chronic autoimmune disorder, is mediated through the overproduction of cytokine and thereby produces hyperplasia (Bowcock and Krueger, 2005). When considering the pathogenesis of psoriasis, it has assumed that the IL-23, a cytokine mediates build-up of IL-17 and IL-22, thereby produces the Th17 cell, a primary target in autoimmune inflammatory disease, and therefore develops the psoriatic circumstance (Azfar and Gelfand, 2008). Also, it has observed that overexpression of Th17 and IL23 cells has established in diseased psoriatic conditions (Lee et al., 2004; Lowes et al., 2008; Piskin et al., 2006). Experimentally, the intramuscular injection of IL-23 in mice skin lead to developing the erythematic and hyperplasia a psoriatic condition (Chan et al., 2006; Zheng et al., 2007), which ameliorated through the reduction of Th17 cell response to the skin (Haider et al., 2008; Zaba et al., 2007).

To investigate the efficacy of EJTL ointment in treating inflammatory skin diseases, like psoriasis, this study has performed in our laboratory. The continuous application of IMQ results in the augmented ear thickness and redness of the ear. Besides, the H\&E stained tissue sections of IMQ treated skin showed increased skin thickening, i.e., acanthosis through distressed keratinocytes; parakeratosis, a condition where the retention of the nuclei in the stratum corneum was observed. On the application of Vaseline did not show any effect on skin inflammation. The observed anti-psoriatic activity may be through the inhibition of keratinocyte proliferation, which may be attributed to the presence of various phytoconstituents, especially Isolariciresinol and flavonoids, in the EJTL extract.

Table 2. Histopathological reports.

\begin{tabular}{|c|c|c|}
\hline Group & Group description & Hematoxylin and eosin stained sample reports \\
\hline 1. & Negative control & The dermis appeared normal \\
\hline 2. & Positive control & $\begin{array}{l}\text { There is the retention of nuclei in the stratum corneum of the skin. Together to this, the sections showed } \\
\text { pinna with moderate hyperkeratosis, keratin flaking, and the upper dermis showed many lymphocytes } \\
\text { and the absence of granular cell layer. Also, there is no elongation of rete-ridges, and there is a dense } \\
\text { infiltration by polymorphs in the parakeratosis layer. }\end{array}$ \\
\hline 3. & $\begin{array}{l}\text { Treatment group EJTL ointment } \\
\left(100 \mathrm{mg} / \mathrm{cm}^{2}\right)\end{array}$ & $\begin{array}{l}\text { The epidermis with thinning of granular cell layer indicating that it influences to retard the } \\
\text { hyperproliferation of the keratinocytes that occurs when the skin exposed to the IMQ application. Also, it } \\
\text { shows a dense infiltration by lymphocytes and polymorphs and pinna with skin having mild hyperkeratosis } \\
\text { and moderate lymphocytic infiltration. Moreover, the granular cell layer has appeared as usual. }\end{array}$ \\
\hline 4. & $\begin{array}{l}\text { Standard group clobetasol } \\
\text { propionate cream }\left(40 \mathrm{mg} / \mathrm{cm}^{2}\right)\end{array}$ & Sections show pinna with skin having mild hyperkeratosis, and the dermis is normal. \\
\hline
\end{tabular}


On careful observation of the histopathological studies, IMQ treatment showed that the overexpression and stain were spread additionally throughout the epidermis (Fig. 4 and Table 2). Thus, upon treatment with IMQ induces proliferation and parakeratosis experienced, the absence of a granular layer confirms the psoriatic conditions. However, the EJTL ointment produced noticeable changes in the epidermis of the IMQ infected mice skin showed a characteristic expression in the greater stratum corneum of the epidermis confirms its potential to use as an anti-psoriatic agent.

\section{CONCLUSION}

The present study revealed the presence of primary phytochemicals, such as flavonoids and lignans from its ethanolic extract of the leaves of J. tranquebariensis L. The Spectral studies showed the presence of the functional groups, Isolariciresinol present in it. However, the in vivo evaluation of the EJTL ointment was shown the remarkable anti-psoriatic activity in Balb/c mice with IMQ induced psoriasis-like inflammation. In addition to this, a histopathological study revealed the decrease in relative epidermal thickness of the skin and as well improved the skin lesion when compared to the positive control group. Whereas, there is a prominent decrease in lymphocyte and keratinocyte infiltration in the dermis, confirms its use in Siddha for skin infections. Hence, the leaves of $J$. tranquebariensis, which have anti-psoriatic effects, could be a potential drug for psoriatic arthritis either individually or synergistically with other herbs or antipsoriatic agents.

\section{CONFLICT OF INTEREST}

All authors declared that there is no competing interest.

\section{FINANCIAL SUPPORT}

\section{None.}

\section{REFERENCES}

Akilandeswari S, Kumarasundari SK, Valarmathi R, Manimaran S, Sivakumar M. Studies on Anti-inflammatory activity of leaf extract of Justicia tranquebariensis L. Indian J Nat Prod, 2001; 17(1):14-16.

Azfar RS, Gelfand JM. Psoriasis and metabolic disease: epidemiology and pathophysiology. Curr Opin Rheumatol, 2008; 20:416-22.

Blauvelt A. T-helper 17 cells in psoriatic plaques and additional genetic links between IL-23 and psoriasis. J Invest Dermatol, 2008; 128(5):1064-67.

Bowcock AM, Krueger JG. Getting under the skin: the immunogenetics of psoriasis. Nat Rev Immunol, 2005; 5:699-711.

Chan JR, Blumenschein W, Murphy E, Diveu C, Wiekowski M, Abbondanzo S, Lucian L, Geissler R, Brodie S, Kimball AB, et al. IL-23 stimulates epidermal hyperplasia via TNF and IL-20R2-dependent mechanisms with implications for psoriasis pathogenesis. J Exp Med, 2006; 203:2577-87.

Fujisawa H, Shivji GM, KondoS, Wang B, Tomai MA, Miller RL, Sauder DN. Effect of a novel topical immunomodulator, S-28463, on keratinocyte cytokine gene expression and production. J Interf Cytok Res, 1996; 16:555-59.

Gibson SJ, Lindh JM, Riter TR, Gleason RM, Rogers LM, Fuller AM, Oesterich JL, Gorden KB, Qiu X, McKane SW. Plasmacytoid dendritic cells produce cytokines and mature in response to the TLR7 agonists, imiquimod and resiquimod. Cell Immunol, 2002; 218:74-86.
Haider AS, Lowes MA, Suarez-Farinas M, Zaba LC, Cardinale I, Khatcherian A, Novitskaya I, Wittkowski KM, Krueger JG. Identification of cellular pathways of "type 1," Th17 T cells, and TNF- and inducible nitric oxide synthase-producing dendritic cells in autoimmune inflammation through pharmacogenomic study of cyclosporine a in psoriasis. J Immunol, 2008; 180:1913-1920.

Harborne JB. Phytochemical methods: a guide to modern techniques of plant analysis. Chapman and Hall Ltd, London, UK, p 279, 1973.

Jiju V. Investigation of In-vitro Antihelmenthic Activity of Justicia tranquebariensis, World J Pharma Res, 2015; 4(6):902-906.

Kono T, Kondo S, Pastore S, Shivji GM, Tomai MA, McKenzie RC, Sauder DN. Effects of a novel topical immunomodulator, imiquimod, on keratinocyte cytokine gene expression. Lymphokine Cytok Res, 1994; 13:71-6.

Krishnamoorthi R, Ratha Bai V. Phytochemical analysis and antioxidant property of Justicia tranquebariensis. Int J Pharmacogn, 2015; 2(5):254-8.

Kumaresh P, Chowdhury HR. Phytochemical and antioxidant studies of Justicia gendarussa Burm. F. An ethnomedicinal plant. Int J Pharm Sci Res, 2015; 6(8):3454-62.

Lee E, Trepicchio EL, Oestreicher JL, Pittman D, Wang F, Chamian F, Dhodapkar M, Krueger JG. Increased expression of interleukin 23 p19 and p40 in lesional skin of patients with psoriasis vulgaris. J Exp Med, 2004; 199:125-30.

Leslie F, Sabine M, Jane SA, Voerman MK, Louis B, Jon DL, Ferry C, Anne-Marie M, Edwin F, Errol PP, Erik L. Imiquimod-induced psoriasis-like skin inflammation in mice is mediated via the IL-23/IL-17 Axis1. J Immunol, 2009; 182:5836-45.

Lowes MA, Kikuchi T, Fuentes-Duculan J, Cardinale I, Zaba LC, Haider AS, Bowman EP, Krueger JG. Psoriasis vulgaris lesions contain discrete populations of Th1 and Th17 T cells. J Invest Dermatol, 2008; 128:1207-11.

Nadeem A, Ahmad SF, Al-Harbi NO, El-Sherbeeny AM, AlHarbi MM, Almukhlafi TS. GPR43 activation enhances psoriasis-like inflammation through epidermal upregulation of IL-6 and dual oxidase 2 signaling in a murine model. Cell Signal, 2017; 33:59-68.

Nakaguma H, Kambara T, Yamamoto T. Rat ultraviolet ray B photodermatitis: an experimental model of psoriasis vulgaris. Int J Exp Pathol, 1995; 76:65-73.

Palamara FS, Meindl MH, Luhrs P, Stingl G, Sibilia M. Identification and characterization of pDC-like cells in normal mouse skin and melanomas treated with imiquimod. J Immunol, 2001; 173:3051-61.

Parisi R, Symmons DPM, Griffiths CEM, Ashcroft DM. Identification and management of psoriasis and associated comorbidity (IMPACT) project team. Global epidemiology of psoriasis: a systematic review of incidence and prevalence. J Invest Dermatol, 2013; 133(2):37785

Pavithra T, Hari V, Lavanya P, Aruna Kumari T, Rupesh KM, Bhaskar RK. Pharmacological review on Justicia tranquebariensis Linn. Int J Curr Adv Res, 2017; 6(2):2058-61.

Piskin GR, Sylva-Steenland M, Bos JD, Teunissen MB. In vitro and in situ expression of IL-23 by keratinocytes in healthy skin and psoriasis lesions: enhanced expression in psoriatic skin. J Immunol, 2006; 176:1908-15.

Radhika J, Sathya S, Jyothi G, Japasheba JL. Cardioprotective role of Justicia tranquebariensis Linn. Leaf extract in isoproterenol induced myocardial infarction in albino rats. J Appl Pharm Sci, 2013; 3(4):124-28.

Raju GVS, Pillai KR. Lignansfrom Justicia tranquebariensis Linn. Indian J Chem 1989; 28:558-61.

Sahira Banu K, Cathrine L. General techniques involved in phytochemical analysis, Int J Advan Res Chem Sci, 2015; 2(4):25-32.

Saritha B, Brindha P. Review on ethnopharmacognosy of Justicia tranquebariensis $\mathrm{L}$ a traditional siddha drug. Int J Pharm Tech Res, 2013; 5(2):467-74. 
Senthamarai R, Akilandeswari S, Valarmathi R. Anti-arthritic activity of Cissus quadrangularis and Justicia tranquebariensis in the treatment of rheumatism. Int J Pharm Chem Sci, 2013; 2(3):1435-40.

Shabana BM, Muhammad IMH, Burkanudeen A. Evaluation of antibacterial activity of leaves of Justicia tranquebariensis L. Pharmacist, 2008; 3(1):35-7.

Shabana BM, Muhammad IMH, Burkanudeen A. Protective and curative effects of Justicia tranquebariensis linn leaves in acetaminophen induced hepatotoxicity. Int J Pharm Biol Arch, 2011; 2(3):989-95.

Shabana BM, Muhammad IMH. Antiulcerogenic Effect of Justicia tranquebariensis in Ethanol Induced Gastric Ulcer in Albino Mice. Mcas J Res, 2015; 2:12-21.

Singhal M, Kansara N. Cassia tora Linn cream inhibits ultraviolet-B-induced psoriasis in rats. ISRN Dermatol, 2012; 2012:346510.

Velpandian V, Elangovan S, Naansi A, Mohamed M. Clinical evaluation of Justicia tranquebariensis L, in the management of bronchial asthma. Am J Phytomedicine Clin Ther, 2014; 2(9):1103-11.

Wagner TL, Ahonen CL, Couture AM, Gibson SJ, Miller RL, Smith RM, Reiter MJ, Vasilakos JP, Tomai MA. Modulation 5844 IL-23/ IL-17-Mediated psoriasis-like skin of TH1 and TH2 cytokine production with the immune response modifiers, R-848 and imiquimod. Cell Immunol, $1999 ; 191: 10-19$.

Xiao P, Huang H, Chen J, Li X. In vitro antioxidant and antiinflammatory activities of Radix isatidis extract and bio accessibility of six bioactive compounds after simulated gastro-intestinal digestion. J Ethnopharmacol, 2014; 18:157:55-61.
Yujiao M, Mingxing W, Xiangjiang X, Tingting D, Jingxia Z, Yan L, Xiaolong X, Ningfei L, Yating Z, Yan W, Ping L. Paeonol ameliorates imiquimod-induced psoriasis-like skin lesions in BALB/c mice by inhibiting the maturation and activation of dendritic cells. Int J Mol Med, 2017; 39:1101-10.

Zaba LC, Cardinale I, Gilleaudeau P, Sullivan-Whalen M, Suarez FM, Fuentes-Duculan J, Novitskaya I, Khatcherian A, Bluth MJ, Lowes MA, Krueger JG. Amelioration of epidermal hyperplasia by TNF inhibition is associated with reduced Th17 responses. J Exp Med, 2007; 204:3183-94.

Zheng Y, Danilenko DM, Valdez P, Kasman I, Eastham-Anderson $\mathrm{J}$, Wu J, Ouyang W. Interleukin-22, a TH17 cytokine, mediates IL-23induced dermal inflammation and acanthosis. Nature, 2007; 445:648-51.

\section{How to cite this article:}

Bharathi D, Subbiah L, Thangavelu P, Palanisamy S. Assessment of anti-psoriatic activity of ethanolic extract of Justicia tranquebariensis Linn. on amelioration of IMQinduced hyperkeratosis in Balb/C mice. J Appl Pharm Sci, 2020; 10(12):083-089. 